\title{
Evaluation of Serum Level of Salusin Beta in Psoriatic Patients
}

\author{
S.H.Ahmed ${ }^{1}$, E.M.Akl ${ }^{1}$, N.A.AbdulHafez ${ }^{2}$, E.E.Shehata ${ }^{3}$ and S.M. Abd El Aal ${ }^{1}$
}

${ }^{1}$ Dermatology, Venereology and Andrology Dept., Faculty of Medicine, Benha Univ., Benha

${ }^{2}$ Clinical Pathology and Immunology Dept., Faculty of Medicine, Benha Univ., Benha, Egypt

${ }^{3}$ Cardiology Dept., Faculty of Medicine, Ain Shams Univ., Egypt

E-Mail:Shady@gmail.com

\begin{abstract}
Psoriasis is a chronic, immune-mediated, inflammatory disease of the skin. It is a multifactorial malady with hereditary foundation activated by enviromental factors and immunological middle people. Numerous Epidemiologic examinations proposed that patients with psoriasis are at expanded danger of cardiovascular disease.To assess serum salusin beta level in psoriatic patients. In this relative case-control study, 50 psoriatic patients (case gathering) and 30 age-and sexual orientation coordinated solid people filling in as a benchmark group, were chosen from the outpatients' facilities of the Dermatology, Venereology, and Andrology Department, Faculty of Medicine, Benha University, during the period from October, 2018 to May, 2019. This investigation found that the serum salusin- $\beta$ levels were signifcantly higher in psoriasis patients contrasted with control group.This study found that the serum salusin- $\beta$ levels were signifcantly higher in psoriasis patients contrasted with control gathering.
\end{abstract}

Keywords: Salusin beta, Psoriatic, Diabetes mellitus.

\section{Introduction}

Psoriasis is a ceaseless, immune-mediated illness influencing around 100 million individuals around the world. Psoriasis influences people all things considered and can show in a wide range of structures, the most well-known being psoriasis vulgaris (or plaque psoriasis). Plaque psoriasis is portrayed by patches of erythema canvassed in a silvery-white scale, which is the aftereffect of quick hyperproliferation and dysregulated separation of epidermal keratinocytes [12].

The etiology of psoriasis is multifactorial and incorporates an unpredictable interchange of hereditary, natural, irresistible and way of life factors [3]. Genome-wide affiliation considers have distinguished various psoriasis-associated quality loci including the Human leukocyte antigen (HLA)-Cw6 quality explicitly the HLA-class 1 allele, HLA-C, situated inside Psoriasis Susceptibility Locus 1 (PSORS1 on 6p21.3) [25]. Different variations, are identified with natural insusceptible pathways, antigen introduction, and T-cell actuation and separation [15].

Salusin- $\beta$ is a strong bioactive peptide that was initially anticipated utilizing in silico investigation of a human cDNA library [20]. Salusin- $\beta$-like immunoreactivity was later shown in human plasma and pee [6]. Salusin- $\beta$ applies consolidated fundamental and neighborhood organic activities, including hypotensive and bradycardic impacts, that are intervened by means of foundational parasympathetic incitement and negative cardiotropic inotropism. Focal salusin- $\beta$ directs hemodynamic homeostasis by actuating antidipsogenesis, circulatory strain height and incitement of vasopressin and oxytocin discharge. Fringe exercises of salusin- $\beta$ incorporate its intense proatherosclerotic impacts and concealment of cardiovascular renovating. Notwithstanding such overpowering organic exercises, it has likewise been proposed as a biomarker for certain human maladies [19].
Metabolic Syndrome (MS) is characterized as a group of hazard factors including focal stoutness, atherogenic dyslipidemia, hypertension and glucose narrow mindedness, is a solid indicator of cardiovascular illness. Expanded mortality from cardiovascular infection in patients with serious psoriasis has been archived and psoriasis might be a free hazard factor for myocardial dead tissue, particularly in youthful patients. Psoriasis is related with MS, free of its seriousness. A few variables may add to a horrible cardiovascular hazard profile in patients with psoriasis, for example, cigarette smoking, liquor utilization, corpulence, physical idleness, homocysteinemia, mental pressure, and misery, which are all increasingly predominant in patients with psoriasis [14].

\section{Aim of the work}

The aim of this study is to evaluate serum salusin beta level in psoriatic patients.

\section{Subjects and methods}

Study Type: This examination is a near case-control study.

Ethical Consideration: This examination was done after endorsement of the Dermatology, Venereology and Andrology Department and the Ethics advisory group of Faculty of Medicine, Benha University.

Subjects and strategies: In this relative case-control study, 50 psoriatic patients (case gathering) and 30 age-and sex coordinated sound people filling in as a benchmark group, were chosen from the outpatients' facilities of the Dermatology, Venereology, and Andrology Department, Faculty of Medicine, Benha University, during the period from October, 2018 to May, 2019.

Consideration rules: Patients experiencing psoriasis vulgaris with the accompanying measures:

Patients with summed up plaque psoriasis. Psoriasis zone and seriousness file (PASI) score > 8. Age: over 
18 years of age. Length of the malady > a half year. Sex: the two guys and females.

Prohibition rules: Patients who got any fundamental or skin treatment for psoriasis inside the a month or fourteen days individually preceding the examination. Pregnant or lactating female patients. Patients experiencing any fundamental (hepatic, renal sickness) or other dermatological maladies.

\section{Subjects}

Definite ace sheet is introduced in reference section A. The two patients and controls were exposed to the accompanying.

\subsection{Methods}

A. Clinical assessment:

All patients were exposed to the accompanying:

\section{Ful history taking including}

Personal history. Present history.

History of present sickness including: Onset, course and term of psoriasis. Nearness of activating variables, for example, clairvoyant pressure and occasional variety. Medication history of past medicines, type, term, reaction and the date of halting the last treatment and history of some other prescriptions. Family ancestry of psoriasis. History of Cardiovascular infection, renal sickness, diabetes mellitus, hypertension, hyperlipidemia, smoking or admission of liquor.

\section{General clinical assessment}

Circulatory strain was assessed by means of physical assessment and was recorded as the normal of two estimations after the members had been sitting for 5 minutes. Body weight was estimated in light attire, without shoes. Body Height was estimated. Weight list (BMI) was determined as the proportion of weight $(\mathrm{kg})$ to tallness $(\mathrm{m} 2)$ squared $(\mathrm{kg} / \mathrm{m} 2)$ accordingly in condition $\mathrm{Wt} / \mathrm{H} 2$.

\section{Dermatological assessment}

Patients were analyzed to decide: site, size, circulation, number of sores. The psoriasis territory and seriousness file (PASI) score was estimated as respects; erythema, thickness, scaling and surface region and both power and degree of the psoriatic plaques were determined (Schmitt and Wozel, 2005).

The different body areas were weighted to mirror teir separate extent of body surface region (BSA).

Patients were grouped by PASI score into: Mild psoriasis: PASI < 7. Moderate psoriasis: PASI $(7-12)$. Extreme psoriasis: PASI $>12$.

\section{Examinations}

Research center examinations:

\section{1- Venous examples were taken as follow}

$80 \mathrm{~m}$ Peripheral blood tests were gathered from patients and controls. Followed by Centrifugation of blood tests to isolate plasma from the blood. Serum tests were put away at $-20{ }^{\circ} \mathrm{C}$.
2- Serum levels of Salusin $\beta$ was estimated by ELISA method (Bioassay Technology Laboratory Korain Biotech Co., Ltd. Feline \# E 1272 Hu. Part \# E 1812004).

Measure method: $0.1 \mathrm{ml}$ of the example cradle was included into the control well (Zero well) at that point, $0.1 \mathrm{ml}$ of each appropriately weakened example was added to each void well and the plate was hatched at $37^{\circ} \mathrm{C}$ for $90 \mathrm{~min}$. $0.1 \mathrm{ml}$ of biotinylated hostile to human salusin B counter acting agent working arrangement into each well were included and the plate was the hatched at $37^{\circ} \mathrm{C}$ for an hour. Plate was washed multiple times. $0.1 \mathrm{ml}$ of arranged $\mathrm{ABC}$ working arrangement were included into each well and the plate was hatched at $37^{\circ} \mathrm{C}$ for $30 \mathrm{~min}$. Plate washed multiple times. $90 \mu \mathrm{l}$ of arranged TMB shading forming was included into each well and the plate was hatched at $37^{\circ} \mathrm{C}$ in dull for $15-20 \mathrm{~min}$. $0.1 \mathrm{ml}$ of arranged TMB stop arrangement was included into each well. The O.D. absorbance was perused at $450 \mathrm{~nm}$ and determined by standard bend.

\subsection{Statistical analysis}

Inforation were gathered, reconsidered, coded and entered to the Statistical Package for Social Science (IBM SPSS) rendition 23. The quantitative information were introduced as mean, standard deviations and extents when their circulation discovered parametric. Additionally, subjective factors were introduced as number and rates. The examination between bunches with respect to subjective information were finished by utilizing Chi-square test. The examination between two free gatherings with quantitative information and parametric dispersion were finished by utilizing Independent t-test. Spearman relationship coefficients were utilized to survey the connection between's two quantitative boundaries in a similar gathering. Recipient working trademark bend (ROC) was utilized to survey the best cut off point for salusin $\beta$ among patients and controls and furthermore between patients with positive and negative pressure ECG with its affectability, particularity, positive prescient worth (PPV), negative prescient worth (NPV) and region under bend (AUC).

The certainty stretch was set to $95 \%$ and the wiggle room acknowledged was set to $5 \%$. Thus, the p-esteem was viewed as noteworthy as the accompanying: $\mathrm{P}>$ 0.05: Non critical. $\mathrm{P} \leq 0.05$ : Significant.

\section{Results}

This study included 50 clinically diagnosed psoriatic patients and 30 age and sex-matched healthy controls. The patients were 32 females (64\%) and 18 males $(36 \%)$ with mean age $41.62 \pm 8.02$ years old (range 26-56). The controls included 30 age and gender-matched healthy volunteers. They were 17 females $(56.7 \%)$ and 13 males $(43.3 \%)$ with mean age $42.73 \pm 7.80$ years old (range 28-56) Tables (1). 
Table (1) Comparison between patients' group and control group regarding demographic data weight, height and BMI.

\begin{tabular}{|c|c|c|c|c|c|}
\hline & & Patients group & Control group & Test value & P-value \\
\hline & & No. $=50$ & No. $=30$ & & \\
\hline Age (years) & Mean \pm SD & $41.62 \pm 8.02$ & $42.73 \pm 7.80$ & $-0.607 \bullet$ & 0.546 \\
\hline & Range & $26-56$ & $28-56$ & & \\
\hline Sex & Females & $32(64.0 \%)$ & $17(56.7 \%)$ & $0.425^{*}$ & 0.515 \\
\hline & Males & $18(36.0 \%)$ & $13(43.3 \%)$ & & \\
\hline Weight (kg) & Mean \pm SD & $84.28 \pm 13.87$ & $80.90 \pm 12.85$ & $1.084 \bullet$ & 0.281 \\
\hline & Range & $58-110$ & $58-105$ & & \\
\hline Height (m) & Mean \pm SD & $1.68 \pm 0.07$ & $1.72 \pm 0.09$ & $-1.956 \bullet$ & 0.05 \\
\hline & Range & $1.56-1.85$ & $1.57-1.89$ & & S \\
\hline BMI $\left(\mathrm{kg} / \mathrm{m}^{2}\right)$ & Mean \pm SD & $29.79 \pm 4.29$ & $27.47 \pm 3.51$ & $2.492 \bullet$ & 0.015 \\
\hline & Range & $22.04-40.4$ & $20.76-35.79$ & & $\mathrm{~S}$ \\
\hline
\end{tabular}

Independent t-test; *: Chi-square test

There was non significant difference between both studied groups regarding age, sex and weight. Patients group had higher height and BMI than control group
$\mathrm{P} \geq 0.05:$ Non significant; $\mathrm{P} \leq 0.05:$ Significant

with significant difference between both studied groups $(\mathrm{P}<0.05)$ Table (1).

Table (2) Clinical history of patients group.

\begin{tabular}{lcc}
\hline & & Patients group \\
\hline Age of onset (years) & & No. $\mathbf{5 0}$ \\
\cline { 2 - 2 } Duration of disease (years) & Mean \pm SD & $28.96 \pm 6.33$ \\
& Range & $13-45$ \\
Family (Hx) & Mean \pm SD & $12.64 \pm 7.20$ \\
& Range & $1-30$ \\
Psoriatic Arthritis & Negative & $45(90.0 \%)$ \\
& Positive & $5(10.0 \%)$ \\
PASI score & No & $38(76.0 \%)$ \\
& Yes & $12(24.0 \%)$ \\
& Mean \pm SD & $14.08 \pm 5.70$ \\
\hline
\end{tabular}

SD: Standard deviations

The mean age of psoriasis onset and duration was $28.96 \pm 6.33,12.64 \pm 7.20$ respectively. The majority had negative family history $(90 \%)$ and only $24 \%$ had
PASI: Psoriasis area and severity index psoriatic arthritis. The mean PASI score was 14.08 \pm 5.70 Table (2).

Table (3) Comparison between patients' group and control group regarding Salusin $\beta$.

\begin{tabular}{lccccc}
\hline & & Patients group & Control group & Test value & P-value \\
\cline { 2 - 4 } & & No. $=\mathbf{5 0}$ & No. $=\mathbf{3 0}$ & & \\
\hline Salusin $\beta(P g)$ & Mean \pm SD & $301.52 \pm 105.10$ & $236.67 \pm 82.93$ & $2.882 \cdot$ & 0.005 \\
& Range & $180-580$ & $110-410$ & & \\
\hline
\end{tabular}

Independent t-test; *: Chi-square test

$$
\mathrm{p}>0.05 \text { : Non significant; } \mathrm{p}<0.05 \text { : Significant }
$$

This table shows that Salusin $\beta$ had higher significant level in patients' group when compared to control group ( $\mathrm{p}=$ 0.005). 


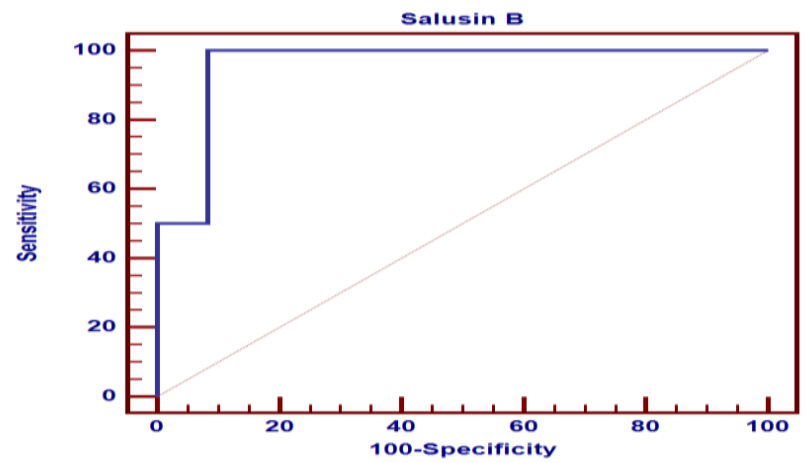

Fig (1) Receiver operating characteristic curve (ROC) for Salusin $\beta$ between patients and controls.

\begin{tabular}{lccccccc}
\hline Variables & $\begin{array}{c}\text { Cut off } \\
\text { point }\end{array}$ & AUC & Sensitivity & Specificity & PPV & NPV & P-value \\
\hline Salusin $\boldsymbol{\beta}$ & $>420$ & 0.958 & 100.00 & 91.67 & 33.3 & 100.0 & 0.0001 \\
\hline
\end{tabular}

$\mathrm{AUC}=$ Area under the curve $\mathrm{PPV}=$ positive predictive value NPV= Negative predictive value.

The Receiver operating characteristic curve (ROC) shows that the best cut off point for Salusin $\beta$ to differentiate between cases and controls was found >
420 with sensitivity of $100 \%$, specificity of $91.67 \%$ and area under curve (AUC) of 0.958 with a highly statistically significant p-value $(<0.001)$.

Table (4) Correlation between Salusin $\beta$ and the other studied parameters in patients' group.

\begin{tabular}{lcc}
\hline & & Salusin $\boldsymbol{\beta}$ \\
\cline { 2 - 3 } & \multicolumn{1}{c}{ p-value } \\
\hline Age (years) & 0.147 & 0.309 \\
Age of onset (years) & -0.097 & 0.503 \\
Duration of disease (years) & 0.295 & 0.037 \\
Weight (kg) & 0.002 & 0.986 \\
Height $(\mathbf{m})$ & 0.038 & 0.795 \\
BMI $\left(\mathbf{k g} / \mathbf{m}^{\mathbf{2}}\right)$ & -0.113 & 0.435 \\
PASI score & 0.720 & 0.000 \\
\hline
\end{tabular}

*r=Spearman correlation coefficients; Bold indicates statistically significant difference $\mathrm{p}<0.05$

Table (4) demonstrates significant positive correlation of salusin $\beta$ to duration of disease $(r=0.295$,

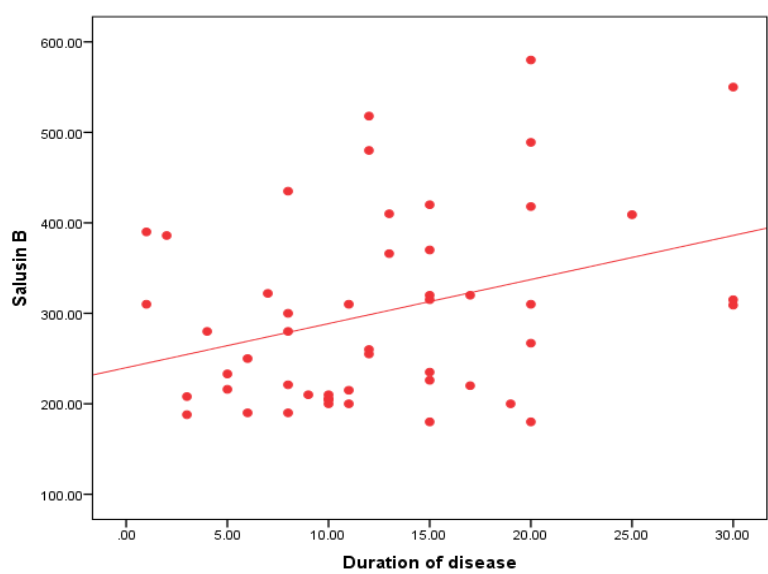

Fig (2) Showing significant positive correlation between Salusin $\beta$ and duration of disease. $\mathrm{p}=0.37)$ and PASI score $(\mathrm{r}=0.720, \mathrm{p}=0.000)$ Figs $(2$, $3)$.

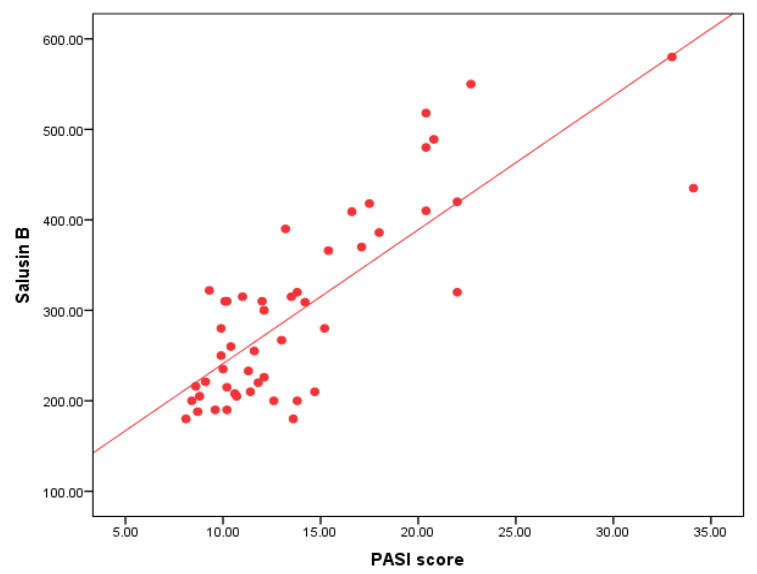

Fig (3) Showing significant positive correlation between Salusin $\beta$ and PASI score. 
Table (5) Relation between Salusin $\beta$ and the other studied parameters in patients' group .

\begin{tabular}{lccccc}
\hline & & \multicolumn{2}{c}{ Salusin $\boldsymbol{\beta}$} & Student & P-value \\
\cline { 3 - 4 } & & Mean \pm SD & Range & & \\
\hline Sex & Femalest & $280.94 \pm 93.06$ & $180-550$ & $1.895 \bullet$ & 0.064 \\
Family (Hx) & Males & $338.11 \pm 117.59$ & $188-580$ & & \\
& Negative & $306.40 \pm 100.62$ & $180-580$ & $0.985 \bullet$ & 0.330 \\
Psoriatic Arthritis & Positive & $257.60 \pm 145.80$ & $180-518$ & & \\
& No & $284.18 \pm 94.40$ & $180-580$ & $2.151 \bullet$ & 0.037 \\
& Yes & $356.42 \pm 122.08$ & $180-550$ & & $\mathrm{~S}$ \\
\hline
\end{tabular}

Independent t-test

Table (5) illustrates that patients with psoriatic arthritis had significant higher mean level of Salusin $\beta$ than those without psoriatic arthritis.

Furthermore, table 5 shows that although male patients and those with negative family history of psoriasis had higher level of Salusin $\beta$ than their counter patients the difference was insignificant $(p>$ $0.05)$.

\section{Discussion}

Psoriasis is described by hyperproliferation and unusual separation of epidermal keratinocytes, lymphocyte invasion for the most part of $T$ lymphocytes and different endothelial vascular changes in the dermal layer, for example, angiogenesis, dilatation and high endothelial venule (HEV) arrangement Guenther and Ortonne [7].

A few investigations exhibited that patients with psoriasis have higher dangers of myocardial localized necrosis, angina, atherosclerosis, fringe vascular ailments, and stroke Wakkee [14]. The immediate advancement of cardiovascular maladies, e.g., by endothelial brokenness brought about by for all time raised degrees of go betweens, for example, VEGF, significantly raises the recurrence of atherosclerosis even among patients with psoriasis who have none of the old style chance components [10].

Mehlis estimated a potential clarification for the relationship among psoriasis and atherosclerosis which is the nearness of constant aggravation that happens in view of persevering discharge of TNF-alpha and other proinflammatory cytokines, for example, interleukin-1 and interleukin-6, which hasten psoriasis.This proinflammatory cytokines invigorate interminable foundational irritation and actuate endothelial brokenness, adjusted glucose digestion and insulin opposition that assume a noteworthy job in the improvement of atherosclerosis [11].

There are two types of Salusin: Salusin- $\alpha$ and Salusin- $\beta$. Salusin- $\alpha$ is probably going to forestall atherosclerosis Watanabe et al., [23], while Salusin- $\beta$ may go about as a potential proatherogenic factor [27].

Shichiri et al. [20] found Salusin- $\alpha$ in human incipient organism. PreproSalusin is communicated in various pieces of the focal sensory system Shichiri et al., [20], Suzuki et al., [21]. Salusins are generally $\mathrm{p}>0.05$ : Non significant; $\mathrm{p} \leq 0.05$ : Significant.

found in various districts of the cerebrum, in the safe framework and in numerous tissues in the body, Salusin- $\alpha$ and Salusin $\beta$ likewise were resolved in human serum and pee (Sato et al., 2006).

Studies on Salusins were basically centered around their relationship with the cardiovascular framework. It has been demonstrated that Salusin $\beta$ diminishes pulse and circulatory strain when administrated intravenously in rodents [8].

In this investigation our point was to assess serum salusin beta level in psoriatic patients.

This examination was led on 50 psoriatic patients (bunch An) and 30 age and sex coordinated solid control subjects (bunch B).

This examination uncovered that the mean serum level of Salusin- $\beta$ was altogether higher $(p<0.05)$ in psoriatic patients contrasted with control subjects.

Aftereffects of this examination concurred with Erden et al. [5] who found that serum Salusin- $\beta$ levels were fundamentally higher in psoriatic patients contrasted with control gathering. As far as we could possibly know, Salusin- $\beta$ was estimated in psoriatic patients in a single report as it were. $\mathrm{Xu}$ et al. [24]; Cakir et al. [1]; Zhou et al. [25] additionally detailed that Salusins are related with aggravation and oxidative pressure.

In the interim Salusin- $\beta$ levels were seen as essentially higher in other immune system sicknesses which are portrayed by aggravation like psoriasis, As Ozgen et al. [16]; Erden [4] examined whether Salusins were related with aggravation and fiery illnesses and found that serum Salusin- $\alpha$ levels and Salusin- $\beta$ levels were higher in patients with Behcet sickness.

Moreover, Cakir [2] found that serum Salusin- $\beta$ levels were essentially higher in Relapsing-Remitting Multiple Sclerosis (RRMS) patients than in control gathering, realizing that RRMS is an immune system illness of focal sensory system and its pathology is described by irritation.

Inthis examination there was a critical positive connection between's the serum levels of Salusin- $\beta$ with the span and seriousness of psoriasis. This examination additionally found that patients with psoriatic joint inflammation had noteworthy higher mean degree of Salusin- $\beta$ than those without psoriatic joint pain. So also Koya et al. [9]; Zhou [26] revealed 
that Salusin- $\beta$ builds irritation through initiation of NF$\mathrm{kB}$.

Additionally, Sato [17] in an in vitro examination expressed that monocyte/macrophage cells discharge Salusin- $\beta$ in the wake of being animated by tumor putrefaction factor alpha (TNF- $\alpha)$ and lipopolysaccaride.

Unexpectedly, Cakir [2] found that there was no huge connection between's the plasma Salusin- $\beta$ levels and the illness span of Multiple sclerosis which is likewise an immune system issue described by aggravation.

Erden et al. [4] additionally detailed that psoriasis was a hazard factor for subclinical atherosclerosis. Erden et al. [5] likewise found that there was a critical increment in hazard factor for atherosclerosis in psoriasis with low degree of Salusin- $\alpha$ and significant levels of Salusin- $\beta$ and that his outcomes were predictable with writing.

Niepolski et al [13] revealed that by breaking down numerous investigations on Salusins and their relationship with atherosclerosis and lipid unsettling influences, They accepted that the metabolic reliance may exist between them, Also detailed that the statement of Salusin- $\beta$ is related with more regrettable lipid profiles. Niepolski et al. [13] likewise revealed that the specific relationship and instruments by which Salusins influence lipid digestion and atherosclerosis stay hazy and that further examinations are expected to fathom these issues.

Taking everything into account high serum levels of Salusin- $\beta$ in psoriatic patients could be an early aware of research the nearness of subclinical atherosclerosis in coronary veins, and in such cases it is recommended that activity echocardiography or radionuclide myocardial perfusion imaging could be better and increasingly noteworthy in finding of any conceivable coronary supply route illness or atherosclerosis.

\section{Conclusion}

This investigation found that the serum salusin- $\beta$ levels were signifcantly higher in psoriasis patients contrasted with control gathering. In this examination we can infer that high serum level of salusin- $\beta$ in psoriatic patients could be an early aware of research the nearness of subclinical atherosclerosis in coronary veins.

\section{References}

[1] M.Cakir, H.Duzova, A.Taslidere. Protective effects of Salusin-alpha and Salusin-beta on renal ischemia/reperfusion damage and their levels in ischemic acute renal failure.Biotech.Histochem, Vol.92(2), PP.122-133,2017.

[2] M.Cakir, S.Sabah-Özcan, H.Saçmacı. Increased level of plasma Salusin- $\alpha$ and Salusin- $\beta$ in patients with multiple sclerosis. Mult Scler Relat Disord, Vol.30, PP.76-80,2019.
[3] P.Di Meglio, F.Villanova, F.O.Nestle. Psoriasis. Cold Spring Harb Perspect Med, Vol.498, PP. 015354,2014

[4] I.Erden, B.Demir, H.Uçak. Serum Salusin alpha and Salusin beta levels in patients with Behcet's disease.Eur.J.Dermatol, Vol.24 (5), PP.577$582,2014$.

[5] I.Erden, H.Uçak, B.Demir. Serum Salusin-alpha and Salusin-beta levels in patients with psoriasis.Eur.J. Dermatol, Vol.25(4), PP.35253,2015 .

[6] K.Fujimoto, A.Hayashi, Y.Kamata. Circulating levels of human salusin- $\beta$, a potent hemodynamic and atherogenesis regulator. PLoS One, Vol.8, PP. e76714,2013.

[7] L.C.Guenther, J.P.Ortonne. Pathophysiology of psoriasis: science behind therapy. J Cutan Med Surg, Vol.6, PP.2-7,2002.

[8] H.Izumiyama, H.Tanaka, K.Egi. Synthetic salusins as cardiac depressors in rat. Hypertension, Vol.45,P.419-25,2005.

[9] T.Koya, T.Miyazaki, T.Watanabe. Salusin-beta accelerates inflammatory responses in vascular endothelial cells via NF-kappa B signaling in LDL receptor-deficient mice in vivo and HUVECs in vitro. Am. J. Physiol. HeartCirc. Physiol, Vol.303(1), PP.H96-105,2012.

[10]R.J.Ludwig, C.Herzog, A.Rostock. Psoriasis: a possible risk factor for development of coronary artery calcification. $\mathrm{Br} \mathrm{J}$ Dermatol, Vol.156, PP.271-6,2007.

[11] S.L.Mehlis, K.B.Gordon. The immunology of psoriasis and biologic immunotherapy. J Am Acad Dermatol, Vol.49, PP.44-50,2003.

[12] A.Menter, N.J.Korman, C.A.Elmets. Guidelines of care for the management of psoriasis and psoriatic arthritis: section 6. Guidelines of care for the treatment of psoriasis and psoriatic arthritis: case-based presentations and evidence-based conclusions. J Am Acad Dermatol, Vol.65, PP.137-174,2011.

[13]L.Niepolski, A.E.Grzegorzewska. Salusins and adropin: New peptides potentially involved in lipid metabolism and atherosclerosis. Adv Med Sci, Vol.61(2), PP.282-87,2016.

[14]T.Nijsten, M.Wakkee. Complexity of the association between psoriasis and comorbidities. J Invest Dermatol, Vol.129, PP.1601-3,2009.

[15]P.Nikamo, J.Lysell, M.A.Stahle. Association with Genetic Variants in the IL-23 and NF-kappaB Pathways Discriminates between Mild and Severe Psoriasis Skin Disease. J Invest Dermatol, Vol.135(8), PP.1969-76. ,2015.

[16] M.Ozgen, S.Koca, M.Dagli. Serum Salusin alpha level in rheumatoid arthritis. Regul. Pept, Vol.167(1), PP. 125-28,2011.

[17] K.Sato, K.Fujimoto, T.Koyama. Release of Salusin-beta from human monocytes/macrophages. Regul. Pept, Vol.162 (1-3), PP.68-72,2010. 
[18] K.Sato, T.Koyama, T.Tateno. Presence of immunoreactive Salusin- $\alpha$ in human serum and urine. Peptide, Vol.27, PP.2561-6,2006.

[19] M.Shichiri, S.Ishimaru, T.Ota. Salusins: newly identified bioactive peptides with hemodynamic and mitogenic activities. Nat Med, Vol.9, PP. 1166-72,2003.

[20] M.Shichiri, H.Izumiyama, T.Watanabe. Salusins in Handbook of Biologically Active Peptides (ed Abba J. Kastin) Ch, Vol.193, PP.1423-27, 2013.

[21] N.Suzuki, M.Shichiri, T.Tateno. Distinct systemic distribution of Salusin- $\alpha$ and Salusin- $\beta$ in the rat. Peptides, Vol.32, PP.805-10,2011.

[22]M.Wakkee , T.Nijsten. Comorbidities in dermatology. Dermatol Clin, Vol.27(2), PP.13747,2009.

[23] T.Watanabe, K.Nishio, T.Kanome. Impact of Salusin-alpha and -beta on human macrophage foam cell formation and coronary atherosclerosis. Circulation, Vol.117(5), PP.638-48,2008.

[24] T.Xu, Z.Zhang, T.Liu. Salusin-beta contributes to vascular inflammation associated with pulmonary arterial hypertension in rats. J. Thorac. Cardiovasc. Surg, Vol.152(4), PP. 177-1187,2016.
[25]B.Zhou, L.Ling, X.Q.Xiong. Salusin-beta contributes to oxidative stress and inflammation in diabetic cardiomyopathy. Cell Death Dis, Vol.8(3), PP. e2690,2017.

[26] C.H.Zhou, L.Liu, L.Liu. Salusin-b not salusin-a promotes vascular inflammation in ApoE-deficient mice via the $\mathrm{I}-\mathrm{kBa} / \mathrm{NF}-\mathrm{kB}$ pathway. PLoS One, Vol.9, PP.e91468,2014.

[27] C.H.Zhou, L.L.Liu, Y.Q.Wu. Enhanced expression of Salusin- $\beta$ contributes to progression of atherosclerosis in LDL receptor deficient mice.Can J Physiol Pharmacol, Vol.90(4), PP.463-71,2012.

[28]F.Zhou, H.Cao, X.Zuo. Deep sequencing of the MHC region in the Chinese population contributes to studies of complex disease. Nat Genet, Vol.48, PP.740-46,2016.

[29] J.Schmitt , G.Wozel. The psoriasis area and severity index is the adequate criterion to define severity in chronic plaque-type psoriasis. Dermatology, Vol.210(3), PP. 194-9,2005. 